\title{
УДК 691.3
}

\section{ВЫСОКОЭФФЕКТИВНЫЕ САМОУПЛОТНЯЮЩИЕСЯ ПОРОШКОВО- АКТИВИРОВАННЫЕ ПЕСЧАНЫЕ БЕТОНЫ И ФИБРОБЕТОНЫ}

\author{
Калашников В.И. ${ }^{1}$, Володин В.М. ${ }^{2}$, Ерофеева И.В. ${ }^{1}$, Абрамов Д.А. ${ }^{2}$ \\ ${ }^{1}$ ФГБОУ ВПО «Пензенский государственный университет архитектуры и строительства», Пенза, Россия \\ (440028, Пенза, улииа Г. Титова, дом 28), e-mail: Kalashnikov_vi@mail.ru \\ ${ }^{2}$ Сверхпрочныле экономичные бетоны, г. Ульяновск, е-mail: vladimir.versus@gmail.com
}

В статье предложены многокомпонентные порошково-активированные самоуплотняющиеся песчаные бетоны с повышенным содержанием дисперсных и тонкозернистых компонентов на основе молотых и тонкозернистых кварцевых песков, увеличивающих содержание водно-дисперсной и водно-дисперснотонкозернистой суспензионной составляющих, усиливающих действие суперпластификаторов, превращающих бетонную смесь в саморастекающуюся, самонивелирующуюся под действием собственного веса и самоуплотняющуюся за счет всплывания воздушных пузырьков. Приведены основные физико-технические свойства порошково-активированных песчаных бетонов и фибробетонов нового поколения. Рассмотрено ускорение начального твердения бетонов при введении нанометрических гидросиликатов кальция. Применение нанометрических гидросиликатов кальция позволяет значительно ускорить набор прочности бетонов через 8-10 часов при нормальном твердении и осуществлять распалубку изделий. Приведены результаты гигрометрических свойства порошковоактивированных песчаных бетонов и фибробетонов нового поколения.

Ключевые слова: высокопрочный бетон, многокомпонентный бетон, дисперсные компоненты, самоуплотняющийся бетон, фибробетон, прочность, наногидросиликаты кальция.

\section{HIGH-PERFORMANCE SELF-COMPACTING POWDER-ACTIVATED SAND CONCRETE AND FIBER-REINFORCED CONCRETE}

\author{
Kalashnikov V.I. ${ }^{1}$, Volodin V.M. ${ }^{2}$, Erofeeva I.V. ${ }^{1}$, Abramov D.V. ${ }^{2}$ \\ ${ }^{1}$ Penza State University of Architecture and Construction, Penza, Russia (440028, Penza, street G. Titova, 28), e-mail: \\ Kalashnikov_vi@mail.ru \\ ${ }^{2}$ High strength economical concrete,Ulyanovsk, e-mail: vladimir.versus@gmail.com
}

The article suggested multicomponent powder-activated self-sealing sand concrete with high content of finegrained dispersed and components on the basis of ground and fine-grained quartz sand, to increase the content of water-dispersed and water-dispersion-suspension fine-grained components that enhance the effect of superplasticizers, turning the mixture into a self-leveling concrete, self-leveling under its own weight and selfsealing due to floating of air bubbles. The basic physical and technical properties of activated powder-sand concrete and fiber-reinforced concrete of the new generation. Considered the initial acceleration of hardening concrete with the introduction of nanometric hydrosilicates calcium. Application of nanometer hydrosilicates calcium can significantly accelerate the curing of concrete in 8-10 hours at normal hardening and implement stripping products. Results hygrometric properties of powder-activated sandy concrete and fiber-reinforced concrete of the new generation.

Keywords: high-strength concrete, multicomponent concrete, dispersive components, self-compacting concrete, fiber concrete, strength, nanohydrosilicate calcium.

В последние годы во всех индустриально развитых странах расширяется применение высокопрочных и высококачественных многокомпонентных бетонов нового поколения [1, 8, 9] с прочностью на сжатие до 140-150 МПа, а фибробетонов - до 180-220 МПа, что позволяет существенно снизить материалоемкость и повысить долговечность конструкций зданий и сооружений по сравнению с конструкциями из обычных бетонов, выпускаемых в России в объемах 96-97\%, с прочностью 20-40 МПа. 
Фибробетоны удовлетворяют высоким требованиям по прочности на сжатие и растяжение (с дуктильным характером разрушения), по трещиностойкости, ударной вязкости, износостойкости, коррозионной стойкости, морозостойкости [6].

Переход на новые виды современных бетонов обусловлен высокими достижениями в области пластифицирования бетонных и растворных смесей и появлением наиболее активных пуццолановых добавок - микрокремнеземов, дегидратированных каолинов и высокодисперсных зол. В последние годы при производстве высококачественных бетонов реализуется концепция использования реологически-активных мономинеральных и полиминеральных тонкодисперсных порошков микрометрического масштабного уровня на основе молотых горных пород.

Сочетание суперпластификаторов и особенно гиперпластификаторов на поликарбоксилатной и полигликолиевой основах с дисперсными порошками, позволяет снизить водоцементное отношение до 0,24-0,28 и получать сверхтекучие цементноминеральные дисперсные системы и бетонные смеси.

Многокомпонентность современных высококачественных бетонов требует системного подхода к выбору исходных компонентов для его приготовления с целью создания материала различного функционального назначения. Такой подход реализуется путем использования системы критериальных показателей оценки эффективности модифицирующих компонентов и пластифицирующих добавок с целью создания бетонов многофункционального назначения.

Состав и свойства самых распространенных песчаных бетонов (мелкозернистых или пескобетонов), производимых в России, не отвечают прогрессивным техническим и экономическим требованиям в связи с повышенным расходом портландцемента на один кубометр бетона при прочности его на сжатие (M150-M600). При этом удельный расход цемента на единицу прочности при сжатии (Ц $\mathrm{R}_{\mathrm{c}}^{\mathrm{y}}$, кг/МПа) находится в пределах 8-14 кг/МПа и более. Низкая прочность матрицы не позволяет получать высокоэффективные фибробетоны и экономить стальную фибру.

На основе теоретических представлений о возможности достижения максимальных водоредуцирующих эффектов суперпластификаторов в дисперсных цементно-водноминеральных системах показано, что песчаный бетон нового поколения, кроме дисперсного цемента, должен дополнительно включать комбинацию дисперсных и тонкозернистых добавок: молотые природные пески (микрокварц), молотые горные породы вулканического происхождения, молотые известняки, тонкие природные пески или дробленые из горных пород, а также, при необходимости, реакционно-активные пуццоланические добавки, в 
частности микрокремнезем (МК) и при строго оптимальных соотношениях, совместно усиливающих реологическое действие суперпластификаторов или гиперпластификаторов.

Песчаные бетоны нового поколения должны быть 7-8-компонентными с четырехпятикомпонентной водной порошково-активированной матрицей, не только с целью повышения прочности бетонов, но и для существенной минимизации расхода цемента, что позволяет называть такие бетоны порошково-активированными [7].

Соотношение компонентов по массе $\left(\frac{\Pi_{\mathrm{M}}}{Ц}, \frac{\Pi_{\mathrm{T}}}{Ц}, \frac{\Pi_{3}}{Ц}\right)$ и по объему $\left(\frac{\mathrm{V}_{\Pi \mathrm{M}}}{\mathrm{V}_{ц}}, \frac{\mathrm{V}_{\Pi \mathrm{T}}}{\mathrm{V}_{Ц}}, \frac{\mathrm{V}_{\Pi 3}}{\mathrm{~V}_{Ц}}\right)$ должно быть строго оптимизированным, как и значения условных реологических матриц первого рода ( $\left.И_{\mathrm{B} Д}^{\Pi_{\mathrm{T}}}\right)$ и второго рода ( $\left.И_{\mathrm{B} Д \mathrm{~T}}^{\Pi_{3}}\right)[3,2]$.

Выявлено, что в разработанных 7-8-компонентных пластифицированных песчаных бетонах нового поколения путем оптимальных изменений соотношения дисперсных, тонкозернистого, грубозернистого минеральных компонентов, цемента и воды, при расходах цемента 190-720 кг/м³ достигнут низкий удельный расход цемента на единицу прочности 2,94-7,0 кг/МПа для классов бетона по прочности на сжатие В15-В120.

Новая рецептура порошково-активированных песчаных бетонов формирует в бетонной смеси две условные реологические матрицы, классифицируемые по масштабным уровням дисперсности и зернистости компонентов. Показано, что с использованием матриц первого и второго масштабного уровней можно определить условные реологические критерии, характеризующие степень раздвижки зерен тонкозернистого песка фр.0,16-0,63 мм, среднезернистого песка-заполнителя [2, 5]. Исходя из этого, топологическая структура порошково-активированного песчаного бетона характеризуется двумя коэффициентами раздвижки зерен, в отличие от бетонов старого поколения, где коэффициент один.

Впервые установлены численные значения безразмерных соотношений компонентов по массе и объему для 25 составов порошково-активированных песчаных бетонов, а также условные реологические критерии, позволяющие оценить по расходу цемента и свойствам бетона степень оптимальности подбора составляющих бетонов. Для наиболее оптимальных составов с расходами цемента 370-394 кг/м³ получены высокопрочные песчаные бетоны с прочностью до 98-134 МПа из самоуплотняющихся бетонных смесей для бетонирования монолитных конструкций и для заводской технологии сборного железобетона и фибробетона (таблица 1).

Таблица 1

Реотехнологические свойства самоуплотняющейся порошково-активированной песчаной бетонной смеси и физико-технические свойства бетона 


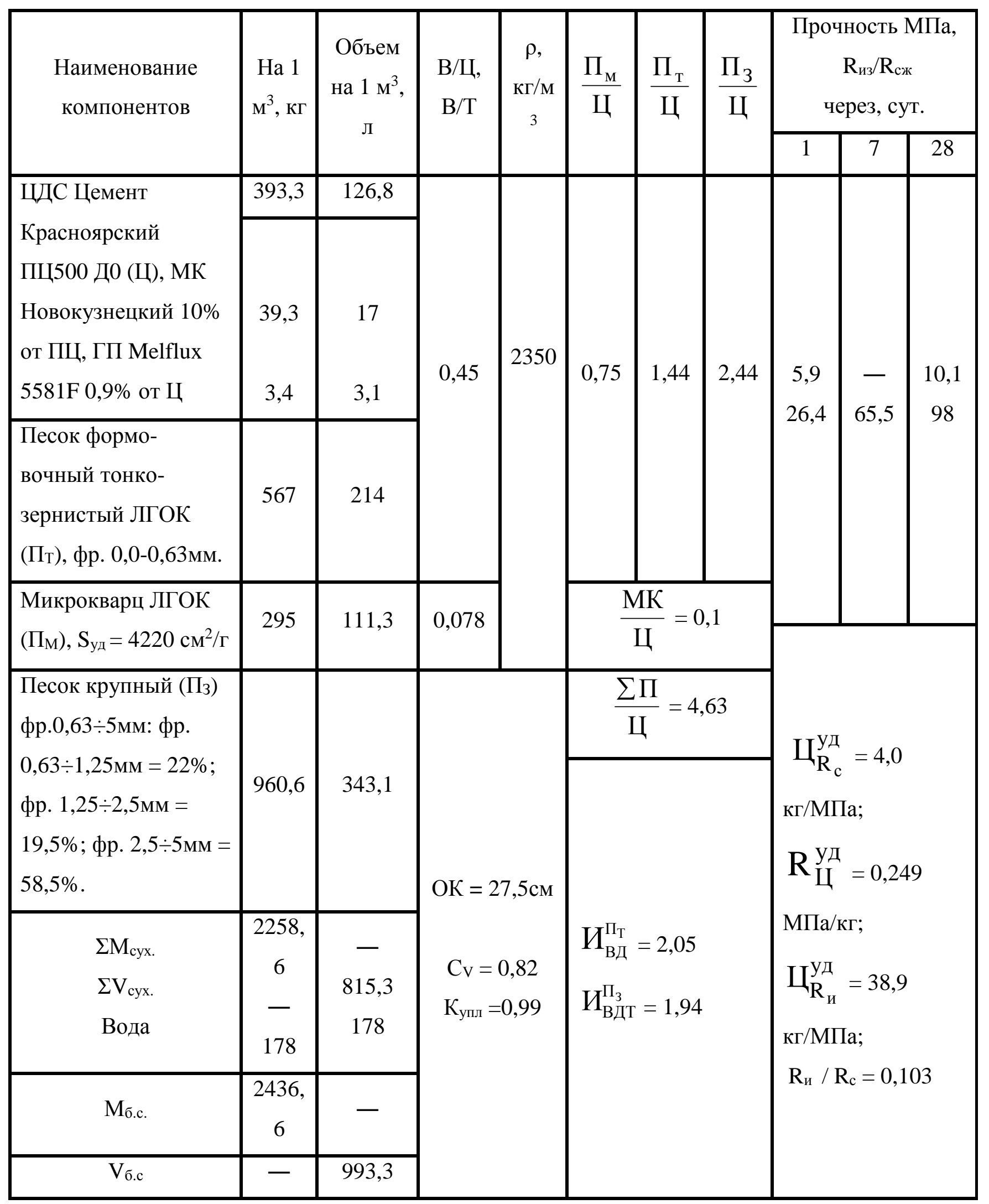

Впервые получен сверхвысокопрочный самоуплотняющийся порошково-активированный

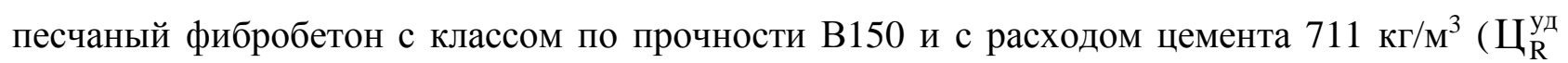
=3,6 кг/МПа), за счет порошковой и тонкозернистой активации его молотым кварцевым 
песком, МК, тонким песком фракции 0,16-0,63 мм с добавлением стальной фибры $3 \%$ и углеродных волокон 0,5\% по объему бетона (таблица 2).

Таблица 2

Реотехнологические свойства самоуплотняющейся порошково-активированной песчаной фибробетонной смеси и физико-технические свойства фибробетона

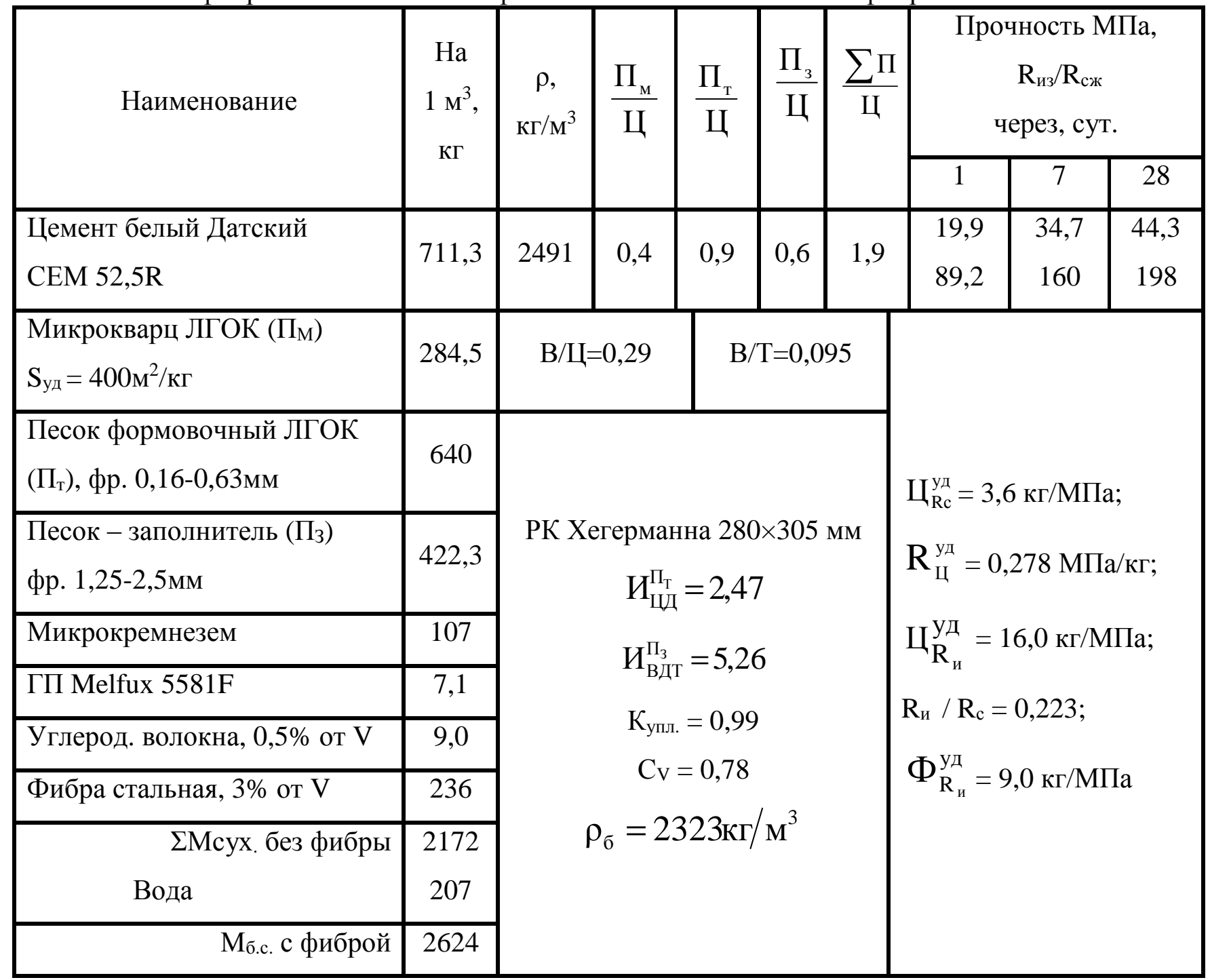

Впервые изучены гигрометрические свойства порошково-активированных песчаных бетонов и фибробетонов. Для фибробетона усадка равна 0,22-0,30 мм/м; водопоглощение через 3 сут от 0,88 до $1,14 \%$ по массе, что позволило получить морозостойкость бетона F1000 без снижения прочности.

Показано, что введение в порошково-активированные песчаные бетоны разработанной нами нанометрической добавки гидросиликатов кальция [4], модифицированной ускорителем твердения и ингибитором коррозии стали, позволяет значительно ускорить набор прочности бетонов через 8-10 ч при нормальном твердении и осуществлять распалубку изделий (таблица 3). 
Таблица 3

Прочностные свойства пластифицированного порошково-активированного песчаного бетона с добавкой нанометрических гидросиликатов кальция и без неё

\begin{tabular}{|c|c|c|c|c|c|c|c|c|c|c|}
\hline \multirow{2}{*}{\multicolumn{2}{|c|}{$\begin{array}{c}\text { Наименование } \\
\text { компонентов и их расход } \\
\text { на } 1 \text { м }^{3} \text { бетона }\end{array}$}} & \multirow[b]{2}{*}{$\begin{array}{l}\text { В/Ц, } \\
\text { В/Т }\end{array}$} & \multirow[b]{2}{*}{$\begin{array}{c}\rho, \\
\kappa \Gamma / \mathrm{M} \\
3\end{array}$} & \multirow[b]{2}{*}{$\begin{array}{c}\text { Конс } \\
\text { истен } \\
\text { ция }\end{array}$} & \multicolumn{6}{|c|}{ Прочность, МПа, через } \\
\hline & & & & & $\begin{array}{c}6 \\
\text { час. }\end{array}$ & \multirow[t]{2}{*}{$\begin{array}{c}8 \\
\text { час. }\end{array}$} & \multirow[t]{2}{*}{$\begin{array}{r}10 \\
\text { час }\end{array}$} & \multirow[t]{2}{*}{$\begin{array}{c}1 \\
\text { сут. }\end{array}$} & \multirow[t]{2}{*}{$\begin{array}{c}7 \\
\text { сут. }\end{array}$} & \multirow[t]{2}{*}{$\begin{array}{l}28 \\
\text { сут. }\end{array}$} \\
\hline \multicolumn{6}{|c|}{ Контрольный состав } & & & & & \\
\hline ПЦ 500 Д0 & 400 & \multirow{7}{*}{$\begin{array}{l}0,387 \\
0,068\end{array}$} & \multirow{7}{*}{2370} & \multirow{7}{*}{$\begin{array}{l}\mathrm{OK}= \\
28 \mathrm{~cm}\end{array}$} & \multirow{7}{*}{$0,1^{*}$} & \multirow{7}{*}{1,0} & \multirow{7}{*}{4,2} & \multirow{7}{*}{43,2} & \multirow{7}{*}{88} & \multirow{7}{*}{116} \\
\hline Микрокремнезем & 40 & & & & & & & & & \\
\hline Микрокварц & 300 & & & & & & & & & \\
\hline $\begin{array}{l}\text { Песок тонкий фр. 0- } \\
0,63 \text { мм }\end{array}$ & 560 & & & & & & & & & \\
\hline Песок средний & 975 & & & & & & & & & \\
\hline Melflux 5581F & 3,6 & & & & & & & & & \\
\hline Вода & 155 & & & & & & & & & \\
\hline \multicolumn{11}{|c|}{ Состав с гидросиликатом } \\
\hline ПЦ 500 Д0 & 391 & \multirow{8}{*}{$\begin{array}{l}0,387 \\
0,068\end{array}$} & \multirow{8}{*}{2360} & \multirow{8}{*}{$\begin{array}{l}\mathrm{OK}= \\
27 \mathrm{~cm}\end{array}$} & \multirow{8}{*}{3,2} & \multirow{8}{*}{10,6} & \multirow{8}{*}{$\begin{array}{c}18, \\
2\end{array}$} & \multirow{8}{*}{44,4} & \multirow{8}{*}{86} & \multirow{8}{*}{110} \\
\hline Микрокремнезем & 39,1 & & & & & & & & & \\
\hline $\begin{array}{l}\text { Гидросиликат } \\
\text { кальция }\end{array}$ & 9,2 & & & & & & & & & \\
\hline Микрокварц & 293 & & & & & & & & & \\
\hline $\begin{array}{l}\text { Песок тонкий } \\
\text { фр. 0-0,63мм }\end{array}$ & 547 & & & & & & & & & \\
\hline Песок средний & 956 & & & & & & & & & \\
\hline Melflux 5581F & 3,5 & & & & & & & & & \\
\hline Вода & 152 & & & & & & & & & \\
\hline
\end{tabular}

* - пластическая прочность.

Как следует из таблицы, действие добавки гидросиликата кальция начинает заметно проявляться между шестью - десятью часами после приготовления смеси. Через 6 часов прочность превышает контрольную в 32 раза, через 8 часов - 10,6 раза и через 10 часов - в 4,3 раза. Через сутки твердения и в дальнейшем прочностные показатели постепенно выравниваются. Важно, что через 9-10 часов возможна распалубливание форм и обеспечение 
твердения изделий при температуре около $20{ }^{\circ} \mathrm{C}$ без проведения тепловлажностной обработки.

Комбинация реологически активных наполнителей микрометрического размера, таких как молотые горные породы, очень тонких песков, суперпластификаторов и наночастиц аморфного кремнезема, наночастиц гидросиликатов кальция может вывести микронанотехнологии бетонов на новый, более перспективный этап беспропарочных и малопропарочных производств.

Полученные результаты работы получили внедрение в ООО «Эммануил» г. Красноярске и ООО «Новые технологии в строительстве» г. Москвы.

\section{Список литературы}

1. Де Шуттер Г. Самоуплотняющийся бетон - путь в будущее // CPI. Международное бетонное производство. - 2013. - №3. - С. 40-45.

2. Калашников В.И. Как превратить бетоны старого поколения в высокоэффективные бетоны нового поколения // Бетон и железобетон. - 2012. - № 1. - С. 82.

3. Калашников В.И. Морозостойкость окрашенных архитектурно-декоративных порошковоактивированных песчаных бетонов / В.И. Калашников, О.В. Суздальцев, М.Н. Мороз, В.В. Пауск // Строительные материалы. - 2015. - № 3. - С. 16-19.

4. Калашников В.И. Наногидросиликатные технологии в производстве бетонов / В.И. Калашников, В.Т. Ерофеев, М.Н. Мороз, И.Ю. Троянов, В.М. Володин, О.В. Суздальцев // Строительные материалы. - 2014. - № 5. - С. 88-91.

5. Калашников В.И. Основные принципы создания высокопрочных и особовысокопрочных бетонов // Популярное бетоноведение. — 2008. - № 3. - С. 102.

6. Калашников В.И. Порошково-активированные сверхвысокопрочные фибробетоны с улучшенной дуктильностью / В.И. Калашников, В.М. Володин, М.О. Коровкин, М.Н. Мороз // Материалы VIII Академических чтений РАACH - Международной научно-технической конференции. Механика разрушения строительных материалов и конструкций. - Казань: КГАСУ, 2014. - С.105-111.

7. Калашников В.И. Что такое порошково-активированный бетон нового поколения // Строительные материалы. - 2012. - № 10. - С. 70-71.

8. European Proect Group «The European Guidelines for Self - Compacting Concrete. Specification, Production and Use». Jjoint work by EFNAPC, BJBM, CEMBUREAU, EFCA, ERMACO. - May, 2005. 
9. Russell, KG. Application of High-Strength Concrete in North America / KG Russell // George C. Hoff Symposium on High-Performance concrete and concrete for marine environ $\neg$ ment. Las Vegas. USA. - May, 2004. - PP. 1-16.

\section{Рецензенты:}

Бузулуков В.И., д.т.н., профессор кафедры физической химии, Мордовский государственный университет имени Н. П. Огарёва, г. Саранск;

Люпаев Б.М., д.т.н., проф., зав. кафедрой автомобильных дорог и специальных инженерных сооружений, Мордовский государственный университет имени Н. П. Огарёва, г. Саранск. 